\title{
Assessment of illness acceptance by patients with COPD and the prevalence of depression and anxiety in COPD
}

This article was published in the following Dove Press journal:

International Journal of COPD

9 May 2016

Number of times this article has been viewed

\author{
Izabella Uchmanowicz' \\ Beata Jankowska-Polanska' \\ Urszula Motowidlo² \\ Bartosz Uchmanowicz' \\ Mariusz Chabowski \\ 'Department of Clinical Nursing, \\ Faculty of Health Science, \\ ${ }^{2}$ Department of Thoracic Surgery, \\ ${ }^{3}$ Division of Nursing in Surgical \\ Procedures, Department of Clinical \\ Nursing, Faculty of Health Science, \\ Wroclaw Medical University, \\ Wroclaw, Poland
}

Background: COPD is a civilization disease. It affects up to $8 \%-10 \%$ of population $>30$ years of age. Coexistence of depression occurs in 20\%-40\% of patients with COPD. Depression and anxiety reduce compliance and worsen prognosis.

Objective: The aims of this study were to determine the degree of illness acceptance among patients with COPD, to examine the relation between disease acceptance and perceived anxiety and depression, and to verify which of the sociodemographic and clinical factors are associated with illness acceptance, anxiety, and depression.

Materials and methods: The study included 102 patients with COPD (mean age 65.8 years), hospitalized due to exacerbations. Acceptance of Illness Scale and Hospital Anxiety and Depression Scale were used. For statistical analysis, Student's $t$-test and Pearson's $r$ correlation coefficient were carried out.

Results: The overall illness acceptance level was moderate with a tendency toward lack of acceptance (mean 20.6, standard deviation [SD] 7.62). The overall scores were 10.2 (SD 3.32) for anxiety and 10.8 (SD 4.14) for depression, which indicate borderline or high intensity of these symptoms. Acceptance of illness was negatively correlated with the intensity of depression symptoms ( $r=-0.46, P<0.05$ ). Intensity of depression was significantly associated with intensity of smoking, duration of the disease, severity of dyspnea, and living in a rural area.

Conclusion: Early identification and assessment of depression and anxiety symptoms allow health care providers to offer patients at risk of depression a special medical supervision. Rapid start of antidepressant therapy may increase illness acceptance and improve prognosis among patients with COPD

Keywords: COPD, depression, anxiety, acceptance of illness

\section{Introduction}

COPD belongs to the group of civilization diseases and has become a huge therapeutic challenge not only in Poland but also worldwide. ${ }^{1}$ The World Health Organization has estimated that $\sim 4$ million people - mainly men - suffer from COPD. By 2030, the number of cases will increase by $65 \%$ and COPD will become the fourth leading cause of death. In Europe, COPD affects up to $8 \%-10 \%$ of population $>30$ years of age. In Poland, the number of patients with COPD had reached 2 million. ${ }^{2}$

Among the causal factors responsible for the development of COPD are smoking ( $~ 80 \%$ of cases), pollution, and susceptibility to infections associated with decreased immunity. Malnutrition, low economic status, and loss of muscle mass have a significant impact on the respiratory system due to the impairment in the functioning of respiratory muscles. Additional risk factors include male sex and genetic burden. ${ }^{3}$
Correspondence: Mariusz Chabowski Division of Nursing in Surgical Procedures, Department of Clinical Nursing, Faculty of Health Science, Wroclaw Medical University, 5 Bartla Street, 5I-618 Wroclaw, Poland $\mathrm{Tel} / \mathrm{fax}+48$ 7I784 I805 Email mariusz.chabowski@gmail.com (c) (1) (5) 2016 Uchmanowicz et al. This work is published and licensed by Dove Medical Press Limited. The full terms of this license are available at https://www.dovepress.com/terms.php C. hereby accept the Terms. Non-commercial uses of the work are permitted without any further permission from Dove Medical Press Limited, provided the work is properly attributed. For permission for commercial use of this work, please see paragraphs 4.2 and 5 of our Terms (https://www.dovepress.com/terms.php). 
COPD decreases the quality of life, generates high costs of treatment, and can cause premature death. ${ }^{4}$ Studies since the last decade have shown that the course of COPD is changeable with variable intensity and strength. COPD is a systemic disease and affects the functioning of many organs; thus, the treatment would be complex with an individualized approach to the patient. Disease management should include personal resources, motivation to change the lifestyle, ability to adapt to the new situation, ability to accept the disease, and, in particular, the willingness to set new goals. ${ }^{5}$ The quality of life in patients with COPD is reduced due to chronic and intensive dyspnea, limitation of physical activity, and frequent hospitalizations. Moderate and severe types of the disease are described by patients as inability to work (34\%), difficulty in planning activities (31\%), loss of control over their own breath (32\%), panic attacks caused by inability to breathe $(37 \%)$, and a sense of continuous deterioration of well-being (41\%). ${ }^{6}$ Dyspnea (65\%), reduction of activity (61\%), fatigue (49\%), and physical discomfort (44\%) are among the most common disease symptoms. ${ }^{7}$ COPD is burdened with high risk of mental health problems, among which depression and anxiety appear to be the most common. Coexistence of depression and COPD has been reported in $~ 20 \%-40 \%$ of patients. Coexistence of COPD and anxiety disorders appears in $30 \%-50 \%$ of patients. Coexistence of these two conditions worsens the physical fitness of patients, impairs their quality of life, causes more frequent use of medical care, and reduces the patient compliance. Anxiety and depression in patients with COPD also increase the risk of death. The onset of depression in patients with COPD worsens the course of COPD due to many reasons and secondarily increases the depressive symptoms. ${ }^{8}$ Additional feelings may appear such as the sense of loneliness, social isolation, low score of selfesteem, lack of faith in the efficacy of treatment, and the lack of goals in life. The coexistence of anxiety disorders and a respiratory disease can subjectively worsen the symptoms of underlying disease, especially dyspnea or cough. This results in greater hospital attendance rate and increases the number and dosages of bronchodilators, inhaled and systemic corticosteroids, and antibiotics, which, as a further result, causes higher incidence and severity of adverse effects. ${ }^{9}$ The more severe the COPD, the heavier the depression. ${ }^{10,11}$

The multidisciplinary model of medical care has been proven to be the most appropriate for patients with COPD associated with symptoms of anxiety and depression. It includes the use of pulmonary and antidepressant medications, pulmonary rehabilitation, cognitive behavioral therapy, support, psychoeducation of the patient and his/her family, and education in the scope of self-coping with the disease. ${ }^{8}$ However, it should also be remembered that, according to the modern paradigm of health, personal resources have a significant impact on functioning of a human with a chronic disease burden. They motivate patients to recovery, and in the case of illness they determine the healing processes. The resources that play an important role in coping with stressful life events include openness; sense of personal control; sense of self-efficacy; belief in themselves, their abilities, and competence; self-reliance; self-esteem; optimism; hope; selfacceptance; sense of humor; sense of coherence; and ability to adapt to unusual situations. ${ }^{12}$ The sense of self-efficacy is the willingness to choose more difficult and/or new tasks, tenacity of purpose, ability to learn new things, and coping with anxiety and stress. ${ }^{13,14}$ Disease acceptance is an important part of adaptation to life with a disease process. The greater the acceptance, the better the adaptation and smaller the sense of discomfort due to illness.

\section{Aim of the study}

The aims of this study were to determine the degree of illness acceptance by patients with COPD, to examine the relation between illness acceptance and perceived anxiety and depression, and to verify which of the sociodemographic and clinical factors are associated with illness acceptance, anxiety, and depression.

Additional detailed assumptions of the study included: 1) Patients declaring lower degree of acceptance of the illness experience anxiety and depression more often than those who declare higher degree of acceptance of the illness. 2) The prevalence of depression and anxiety is associated mainly with exacerbation of the disease symptoms and increase in dyspnea.

\section{Materials and methods}

The study was conducted among 102 patients with COPD (mean age 65.8 years) hospitalized from March 2014 to June 2015, due to exacerbation of their health condition in the Department of Internal Medicine of Lower Silesian Centre for Pulmonary Diseases in Wroclaw. Participation in the study was voluntary and anonymous. All the patients were informed about the aims of the study and the right to withdraw from the research at any time.

Inclusion criteria were as follows: 1) Diagnosis of COPD according to American Thoracic Society/European Respiratory Society in the history made at least 1 year before entering the study. 2) Written informed consent for participation in the study. 
Exclusion criteria were as follows: 1) Coexistence of other chronic diseases such as asthma, active tuberculosis, lung cancer, bronchiectasis, sarcoidosis, pulmonary fibrosis, primary pulmonary hypertension, interstitial lung disease, or other active lung diseases. 2) Hemodynamic instability and severe exacerbation of concomitant chronic disease. 3) The diagnosis of severe mental disorders requiring psychiatric treatment. 4) Lack of the consent for participation in the study.

The study was approved by the Commission of Bioethics at Wroclaw Medical University (consent no KB-683/2014). Standardized questionnaires were used, and medical records were analyzed in order to collect information about diagnosis, severity of the disease, spirometry results, and administered treatment.

The survey developed by the authors included 18 questions related to sociodemographic and clinical data (sex, age, education, number of cigarettes smoked, frequency of hospitalizations, knowledge about the disease, and drugs administered by inhalation).

Acceptance of Illness Scale (AIS) developed by Felton et a ${ }^{15}$ and adapted to Polish conditions by Juczyński ${ }^{16}$ included eight statements and allowed assessing the degree of illness acceptance by the patient. The greater the acceptance of the disease, the less severe the negative reactions and emotions associated with the disease. Each of the statements included 5 -score scale. The patients described their current wellbeing condition by indicating the corresponding number: 1 - strongly agree; 2 - agree; 3 - undecided; 4 - disagree; and 5 - strongly disagree. Wherein, 1 means a bad adaptation to disease and 5 - the highest acceptance of the given condition. The adaptation to the disease is a sum of all points, which is between 8 and 40 points. The authors believe that it can be applied to assess any type of disease. ${ }^{16}$ Modified Hospital Anxiety and Depression Scale (HADS) is one of the most commonly used screening methods for assessment of the level of anxiety and depression among inpatients. Two statements, which assessed the level of aggression, were added to HADS. The maximum score for anxiety and depression is 21 points separately and for aggression 6 points. HADS consists of separate scales. Scores of 0-7 indicate normal levels of anxiety and depression; 8-10 indicate borderline abnormal anxiety and depression levels; and 11-21 indicate high levels, suggesting the disease. Validation of primary and modified version of HADS showed its satisfactory reliability and validity. Spearman's rank correlation coefficient between scale items and overall result of a given subscale was statistically significant at a level of at least $P<0.01$ and ranged between 0.41 and 0.76 .

\section{Statistical analysis}

The obtained results were analyzed using the computer package Statistica software Version 6 (StatSoft, Tulsa, OK, USA). Mean, median, and standard deviation (SD)s were calculated for examined variables. Student's $t$-test was applied for assessment of differences. Two-way analysis of variance allowed for estimating the impact of anxiety and depression on acceptance of the disease. Pearson's $r$ was used to measure correlation between sociodemographic and clinical variables and the levels of illness acceptance (AIS) and anxiety and depression (HADS). Logistic regression method was used to evaluate the predictive value of the independent variables (anxiety, depression) in relation to the dependent variables (acceptance of the disease).

\section{Results}

The study was conducted among 102 patients with COPD, including $37.25 \%$ of women. The average age of surveyed people was 65.8 years (63.2 \pm 6.5 years). More than half of the respondents were married or lived in partnerships (57.8\%). Majority of studied patients lived in cities $(60.8 \%)$ and had preuniversity $(55.6 \%)$ or vocational $(26.5 \%)$ education. They received knowledge about the disease from medical personnel (39.2\% from nurses and 37.3\% from doctors). More than a half of the respondents $(58.8 \%)$ claimed that the level of their knowledge was insufficient (Table 1).

Among the studied patients, majority of them had suffered from COPD for $10-15$ years $(33.3 \%)$. Subsequently, there were people with $5-10$-year disease history $(27.5 \%)$ and those who had been ill for $>15$ years $(22.6 \%)$. Most of the patients had recognized III (severe) (52\%) and II (moderate) $(37 \%)$ stages of the disease. Spirometric classification for the groups were forced expiratory volume in 1 second $\left(\mathrm{FEV}_{1}\right) 1.36 \mathrm{~L}$, forced vital capacity (FVC) 49\% normal, and fixed ratio $\left(\mathrm{FEV}_{1} / \mathrm{FVC}\right)$ 0.61. All the patients were exposed to the main risk factor of COPD $-50 \%$ of respondents smoked $>15$ years. Less than $30 \%$ of respondents smoked up to 10 cigarettes per day, the others smoked 10-20 $(39.2 \%)$ or even more than $20(31.4 \%) ; 40.2 \%$ of patients reported aggravation of symptoms more than twice a day, $16.7 \%$ - every day, and $24.5 \%$ - several times a week. More than half of the respondents (55.9\%) complained of awakening due to shortness of breath three nights or more a week. Only $16.7 \%$ of respondents reported no symptoms during nights. Among studied persons, up to $64.7 \%$ believed that they take inhaled medications skillfully, $10.8 \%$ of them were given oxygen therapy at home, and $>60 \%$ were hospitalized during the last 12 months due to exacerbations. In addition, 
Table I Sociodemographic characteristics of the studied patients

\begin{tabular}{|c|c|c|}
\hline Characteristics & $\operatorname{Me}(\mathbf{M} \pm \mathbf{S D})$ & Min-Max \\
\hline \multirow[t]{2}{*}{ Age, years } & $65.8(63.2 \pm 6.5)$ & $53-76$ \\
\hline & $\bar{n}$ & $\%$ \\
\hline \multicolumn{3}{|l|}{ Sex } \\
\hline Men & 64 & 62.75 \\
\hline Women & 38 & 37.25 \\
\hline \multicolumn{3}{|l|}{ Marital status } \\
\hline Married/in a relationship & 59 & 57.84 \\
\hline Separated/divorced & 22 & 22.57 \\
\hline Widow/widower & 21 & 20.59 \\
\hline \multicolumn{3}{|l|}{ Education } \\
\hline Vocational/primary & 27 & 26.47 \\
\hline Preuniversity & 57 & 55.88 \\
\hline Higher vocational/university & 14 & 13.73 \\
\hline Data not available & 4 & 3.92 \\
\hline \multicolumn{3}{|l|}{ Place of residence } \\
\hline Rural area & 40 & 39.22 \\
\hline Urban area & 32 & 60.78 \\
\hline \multicolumn{3}{|l|}{ Knowledge about COPD } \\
\hline $\begin{array}{l}\text { I believe I know everything on this } \\
\text { topic }\end{array}$ & 7 & 6.86 \\
\hline I know as much as I need to know & 33 & 32.35 \\
\hline I know too little & 60 & 58.82 \\
\hline $\begin{array}{l}\text { I do not know and I do not want } \\
\text { to know }\end{array}$ & 2 & 1.96 \\
\hline \multicolumn{3}{|c|}{$\begin{array}{l}\text { The most useful sources of information helpful in coping } \\
\text { with the disease }\end{array}$} \\
\hline Conversation with a doctor & 38 & 37.25 \\
\hline Conversation with a nurse & 40 & 39.21 \\
\hline Books, leaflets & 19 & 18.63 \\
\hline Television & 5 & 4.9 \\
\hline
\end{tabular}

Abbreviations: Me, median; M, mean; Min, minimum; Max, maximum; N, number of patients; SD, standard deviation.

among the respondents, the following comorbidities were diagnosed: hypertension (46.07\%), coronary artery disease $(32.35 \%)$, heart failure $(28.43 \%)$, diabetes $(18.63 \%)$, and heart arrhythmia (9.8\%) (Table 2).

The assessment of illness acceptance with the use of AIS questionnaire revealed that respondents are mostly characterized by moderate acceptance level with a tendency to the lack of acceptance for their disease (mean 20.6, SD 7.62). Patients worry the most about limitation of their self-sufficiency (mean 2.2, SD 1.20) but the least of being a burden for their family and friends (mean 3.1, SD 1.10) (Table 3). The analysis of anxiety and depression with the use of HADS questionnaire revealed overall scores of 10.2 (SD 3.32) for anxiety and 10.8 (SD 4.14) for depression, which indicate borderline or high intensity of these symptoms (Table 4).

Pearson's product-moment correlation coefficient showed a negative correlation between the level of illness acceptance and the intensity of depression symptoms $(r=-0.46, P<0.05)$, while the level of illness acceptance had no impact on the
Table 2 Clinical characteristics of the studied patients

\begin{tabular}{|c|c|c|}
\hline Clinical characteristics & $\operatorname{Me}(\mathbf{M} \pm \mathbf{S D})$ & Min-Max \\
\hline \multicolumn{3}{|l|}{ Spirometry } \\
\hline $\mathrm{FEV}_{1}, \mathrm{~L}$ & $\mathrm{I} .36(0.7)$ & $0.5 \mathrm{I}-3.50$ \\
\hline $\mathrm{FEV}, \%$, normal & $49(16.3)$ & $15-87$ \\
\hline Ratio of FEV , to FVC & $0.61(0.17)$ & $0.41-1.23$ \\
\hline Characteristics & $\mathbf{n}$ & $\%$ \\
\hline \multicolumn{3}{|l|}{ Duration of the disease } \\
\hline $0-5$ years & 17 & 16.67 \\
\hline $5-10$ years & 28 & 27.45 \\
\hline $10-15$ years & 34 & 33.33 \\
\hline$>15$ years & 23 & 22.55 \\
\hline \multicolumn{3}{|l|}{ Disease severity by GOLD } \\
\hline I & 3 & 3 \\
\hline II & 38 & 37 \\
\hline III & 53 & 52 \\
\hline IV & 8 & 8 \\
\hline \multicolumn{3}{|l|}{ Comorbidities } \\
\hline Hypertension & 47 & 46.07 \\
\hline Coronary artery disease & 33 & 32.35 \\
\hline Heart failure & 29 & 28.43 \\
\hline Diabetes & 19 & 18.63 \\
\hline Heart arrhythmia & 10 & 9.80 \\
\hline \multicolumn{3}{|l|}{ Duration of smoking } \\
\hline $0-5$ years & 22 & 21.57 \\
\hline $5-10$ years & 9 & 8.82 \\
\hline $10-15$ years & 20 & 19.61 \\
\hline$>15$ years & 51 & 50.00 \\
\hline \multicolumn{3}{|c|}{ The number of cigarettes smoked per day } \\
\hline $0-10$ & 30 & 29.41 \\
\hline $10-20$ & 40 & 39.22 \\
\hline$>20$ & 33 & 31.37 \\
\hline \multicolumn{3}{|c|}{ Frequency of dyspnea exacerbations during last month } \\
\hline Once a day & 17 & 16.67 \\
\hline More often than twice a day & 41 & 40.20 \\
\hline Several times a week & 25 & 24.51 \\
\hline Only after physical effort & 19 & 18.63 \\
\hline
\end{tabular}

Frequency of awakening due to COPD symptoms during the last month Once a week $28 \quad 27.45$

$\begin{array}{lll}\text { Three nights a week or more often } \quad 57 & 55.88\end{array}$

$\begin{array}{lll}\text { None } & 17 & 16.67\end{array}$

Hospitalization due to exacerbation of COPD during the last 12 months $\begin{array}{lll}\text { Yes } & 62 & 60.78\end{array}$ No $\quad 40 \quad 39.22$

Ability of taking inhaled medications $\begin{array}{lll}\text { Yes } & 66 & 64.71\end{array}$ No $\quad 36 \quad 35.29$

The use of oxygen at home

$\begin{array}{lll}\text { Yes } & 11 & 10.78 \\ \text { No } & 91 & 89.22\end{array}$

Abbreviations: Me, median; $\mathrm{M}$, mean; Min, minimum; Max, maximum; $\mathrm{FEV}_{1}$, forced expiratory volume in I second; FVC, forced vital capacity; $n$, number of patients; GOLD, Global initiative for chronic Obstructive Lung Disease; SD, standard deviation.

level of anxiety. The lack of comorbidities significantly increased the level of illness acceptance $(r=2.06, P=0.039)$, while dyspnea decreases $(r=-0.24, P=0.015)$. Older age and intensity of dyspnea had a significant impact on increase in 
Table 3 Descriptive statistics for the questions of AIS

\begin{tabular}{|c|c|c|}
\hline Questions from AIS questionnaire & Mean (SD) & $\begin{array}{l}\text { Median } \\
\text { (quartile I-quartile III) }\end{array}$ \\
\hline I have problems with adjusting to the limitations imposed by the disease & $2.4(0.97)$ & $2(2-3)$ \\
\hline Due to my health condition, I am not able to do what I like the most & $2.2(0.95)$ & $2(2-3)$ \\
\hline The disease makes me feel unwanted & $3(3.29)$ & $3(2-3)$ \\
\hline Health problems make me more dependent on others than I would like to be & $2.4(\mathrm{I} . \mathrm{II})$ & $2(2-3)$ \\
\hline The disease makes me a burden for my family and friends & $3.1(1.10)$ & $3(2-4)$ \\
\hline Due to my health condition I do not feel a really valuable man & $2.4(1.19)$ & $2(2-3)$ \\
\hline I will never be as self-sufficient to the extent to which I would like to be & $2.2(1.20)$ & $2(I-3)$ \\
\hline I believe people that stay with me are often embarrassed because of my disease & $2.9(0.92)$ & $3(2-3)$ \\
\hline Overall level of acceptance of illness & $20.6(7.62)$ & $19(16-24)$ \\
\hline
\end{tabular}

Abbreviations: AIS, Acceptance of Illness Scale; SD, standard deviation.

anxiety ( $r=0.37, P=0.000$ and $r=0.23, P=0.020$, respectively). Intensity of depression was significantly positively correlated with duration of smoking ( $r=0.24, P=0.017)$, the number of cigarettes smoked daily ( $r=0.36, P=0.000$ ), duration of the disease $(r=0.36, P=0.000)$, severity of dyspnea $(r=0.27$, $P=0.006)$, and living at the rural area $(r=4.18, P=0.000)$. Higher education significantly reduced depression symptoms $(r=-0.28, P=0.006)$ (Table 5).

\section{Discussion}

We found that in the group of patients with COPD, the prevalence of depression and anxiety had similar level of intensity, and the level of severity of these disorders was borderline or high. However, studies from the literature on psychological condition of patients with COPD report variable intensity of anxiety and depression. According to Wagena et al, ${ }^{10}$ the prevalence of depression in patients with severe COPD is 2.5 times higher than in the control group. In the studies of other researchers, greater intensity of anxiety than depression is observed. ${ }^{17,18}$ Some other studies report greater prevalence of depression than anxiety. ${ }^{19}$

Adaptation to a disease plays a huge role in cases with chronic illnesses. Acceptance of illness is one of the crucial phases that relate patients with their illness. It facilitates the process of adaptation - the process during which a man or a woman adapts to the new situation of living with the disease. ${ }^{16}$ In this study, acceptance level was only 20.6 points, which indicates poor acceptance or its lack. Our findings are consistent with the results obtained by Majda et al. In their study, average illness acceptance rate in 105 patients with COPD hospitalized due to disease exacerbation in selected pulmonary wards from Silesia, Poland, was identical to ours (20.6 points). ${ }^{12}$ Slightly different results were reported by Kupcewicz and Abramowicz ${ }^{20}$ in 96 patients treated due to exacerbations, AIS level was 19 points. In patients suffering from other chronic diseases, the results are comparable. In patients

Table 4 Descriptive statistics for the questions of Hospital Anxiety and Depression Scale (HADS) Questionnaire

\begin{tabular}{|c|c|c|}
\hline Questions from HADS questionnaire & Mean (SD) & $\begin{array}{l}\text { Median } \\
\text { (quartile I-quartile III) }\end{array}$ \\
\hline I feel tense or wound up & $2.5(0.67)$ & $3(2-3)$ \\
\hline I still enjoy the things I used to enjoy & $2.6(0.88)$ & $3(2-3)$ \\
\hline I get a sort of frightened feeling as if something bad is about to happen & $2.6(0.73)$ & $3(2-3)$ \\
\hline I can laugh and see the funny side of things & $2.7(0.8 \mathrm{I})$ & $3(2-3)$ \\
\hline Worrying thoughts go through my mind & $2.6(0.8 I)$ & $3(2-3)$ \\
\hline I feel cheerful & $2.5(0.79)$ & $3(2-3)$ \\
\hline I can sit at ease and feel relaxed & $2.8(0.98)$ & $3(2-4)$ \\
\hline I feel as if I am slowed down & $2.6(0.59)$ & $3(2-3)$ \\
\hline I get a sort of frightened feeling like butterflies in the stomach & $2.2(0.55)$ & $2(2-3)$ \\
\hline I have lost interest in my appearance & $2.6(0.94)$ & $2(2-3.5)$ \\
\hline I feel restless and have to be on the move & $2.6(0.73)$ & $2(2-3)$ \\
\hline I look forward with enjoyment to things & $2.7(0.79)$ & $3(2-3)$ \\
\hline I get sudden feelings of panic & $2.6(0.63)$ & $3(2-3)$ \\
\hline I can enjoy a good book or radio or TV program & $2.6(0.98)$ & $3(2-3)$ \\
\hline It happened that I exploded with anger & $2.6(0.85)$ & $3(2-3)$ \\
\hline It happened that I was upset and angry & $2.4(0.85)$ & $2(2-3)$ \\
\hline Overall anxiety level & $10.2(3.32)$ & $10(8-13)$ \\
\hline Overall depression level & $10.8(4.15)$ & II (8-13) \\
\hline
\end{tabular}

Abbreviation: SD, standard deviation. 
Table 5 Correlation coefficient between acceptance of illness level and anxiety and depression level

\begin{tabular}{|c|c|c|c|}
\hline Variables & Illness acceptance (AIS) & Anxiety (HADS-A) & Depression (HADS-D) \\
\hline \multirow[t]{2}{*}{ Illness acceptance (AIS) } & - & $r=-0.13$ & $r=-0.46$ \\
\hline & & $P=0.31$ & $P<0.05$ \\
\hline \multirow[t]{2}{*}{ Age $>60$ years } & $r=-0.09$ & $r=0.37$ & $r=0.13$ \\
\hline & $P=0.38 \mathrm{I}$ & $P=0.000$ & $P=0.215$ \\
\hline \multirow[t]{2}{*}{ Sex } & $r=0.33$ & $r=0.43$ & $r=1.86$ \\
\hline & $P=0.74 \mathrm{I}$ & $P=0.665$ & $P=0.066$ \\
\hline \multirow[t]{2}{*}{ Education } & $r=0.06$ & $r=-0.01$ & $r=-0.28$ \\
\hline & $P=0.535$ & $P=0.89 \mid$ & $P=0.006$ \\
\hline \multirow[t]{2}{*}{ Duration of smoking } & $r=-0.10$ & $r=-0.12$ & $r=0.24$ \\
\hline & $P=0.340$ & $P=0.255$ & $P=0.017$ \\
\hline \multirow[t]{2}{*}{ Number of cigarettes smoked } & $r=-0.11$ & $r=-0.07$ & $r=0.36$ \\
\hline & $P=0.290$ & $P=0.519$ & $P=0.000$ \\
\hline \multirow[t]{2}{*}{ Duration of the disease } & $r=-0.11$ & $r=-0.07$ & $r=0.36$ \\
\hline & $P=0.290$ & $P=0.519$ & $P=0.000$ \\
\hline \multirow[t]{2}{*}{ Place of residence - rural area } & $r=1.66$ & $r=1.85$ & $r=4.18$ \\
\hline & $P=0.100$ & $P=0.067$ & $P=0.000$ \\
\hline \multirow[t]{2}{*}{ Lack of comorbidities } & $r=2.06$ & $r=0.59$ & $r=1.03$ \\
\hline & $P=0.039$ & $P=0.554$ & $P=0.30 \mathrm{I}$ \\
\hline \multirow[t]{2}{*}{ Intensity of dyspnea } & $r=-0.24$ & $r=0.23$ & $r=0.27$ \\
\hline & $P=0.015$ & $P=0.020$ & $P=0.006$ \\
\hline \multirow[t]{2}{*}{ Yearly number of hospitalizations due to exacerbations } & $r=-0.08$ & $r=-0.09$ & $r=0.25$ \\
\hline & $P=0.457$ & $P=0.353$ & $P=0.014$ \\
\hline
\end{tabular}

Note: Statistically significant correlations are marked in bold.

Abbreviations: AIS, Acceptance of Illness Scale; HADS-A, Hospital Anxiety and Depression Scale - Anxiety; HADS-D, Hospital Anxiety and Depression Scale Depression.

with asthma, illness acceptance rate was 29.4 points and in renal insufficiency patients on dialysis 25 points. $^{21,22}$

In this study, the level of illness acceptance was positively influenced by the lack of comorbidities and negatively by increase in dyspnea. The underlying disease has a significant impact on patients' life because of its chronic nature, differentiated symptoms, and frequency of exacerbations. This impact was confirmed in the studies of Niedzielski et al. ${ }^{23}$ Studies by Kupcewicz and Abramawicz ${ }^{20}$ demonstrated that the longer the duration of the disease, the lower the level of satisfaction of life. In Kieczka' ${ }^{24}$ study, longer duration of the disease was associated with a greater number of people subjected to its negative effect. In this study, similar to the study of Kupcewicz and Abramowicz, ${ }^{20}$ negative influence of comorbidities on illness acceptance was confirmed.

Gift et $\mathrm{al}^{25}$ examined mood as a determinant of illness acceptance in patients on dialysis. Similarly to our findings, they showed that illness acceptance is not significantly associated with any demographic variable; however, statistically significant association appears with all mood dimensions. This relation is negative, so it means that studied patients on dialysis with positive mood have significantly higher level of illness acceptance in comparison with those with decreased mood. ${ }^{25}$
In this study, illness acceptance was significantly correlated with the level of depression. The level of anxiety mainly depended on the severity of symptoms and age of the respondents. Dyspnea is the leading symptom of COPD, and it gradually increases as the disease advances. The coexistence of anxiety disorders with respiratory disease subjectively worsens its symptoms, especially shortness of breath or cough. It results in greater attendance rate and increases the number and doses of bronchodilators, inhaled and systemic corticosteroids, and antibiotics, which cause higher incidence and severity of adverse effects. Many patients do not obtain well-being and effective disease control despite applied treatment. The level of patients' knowledge, their participation in the treatment, and cooperation with doctors are also important factors.

Long-term use of glucocorticoids increases the intensity of symptoms of depression. ${ }^{25}$ Moreover, it is believed that chronic cigarette addiction is associated with intensity of depression. ${ }^{26}$ In this study, all the respondents smoked, either at the time of the study or in the past. Spearman's correlation analysis showed that cigarette smoking was a significant predictor affecting the level of depression.

Studies from the literature confirm that depression has a significant impact on functioning disorders in all dimensions 
of quality of life. It is associated with longer hospital stays and more frequent hospitalizations due to exacerbations. ${ }^{27}$ Authors emphasize the role of other factors that are associated with the intensity of depression symptoms and disease exacerbations that require admissions to hospital such as progression of the disease, female sex, low socioeconomic status, smoking, dyspnea, lack of compliance, inability to cope with the disease, and previous hospitalizations due to exacerbations. ${ }^{27-30}$

In this study, similarly to data from the literature, intensity of dyspnea related to disease progression influenced intensity of depression and anxiety. In parallel as COPD advances, physical, social, and emotional functioning disorders appear as well. ${ }^{11,31}$ This study corresponds to the study of Asnaashari et al, ${ }^{32}$ where the level of depression was associated with the severity of pulmonary obstruction. The relation of intensity of depression symptoms with severity of COPD was confirmed also by other authors. ${ }^{17,33}$ Additionally in our study, the negative impact of the duration of the disease, smoking, and number of cigarettes smoked on the severity of depression symptoms was revealed. Also we found that education and living in rural area influenced the level of depression. The relation may arise from low socioeconomic status, which was regarded important for decreased mood and occurrence of symptoms of depression by other authors. ${ }^{17,34}$ Both our study and those from literature suggest that diagnosis of mood disorders is an important element in the treatment of patients with COPD. Only $27 \%-33 \%$ of patients with depression and COPD are treated with antidepressants. ${ }^{35,36}$ Early diagnosis of anxiety and depression allows introducing management strategies limiting negative effects of depression and enables effective treatment of underlying disease, reduction in hospitalizations, and increase in patient's conscious participation in the therapeutic process. There are already reports describing positive influence of self-care on reduction in hospital stays and number of exacerbations..$^{37,38}$

Actions aimed at improving the mood of patients are the most important and at the same time the least costly. They result in increase in acceptance of illness and can significantly reduce depression symptoms and increase compliance in patients with COPD.

\section{Practical implications}

Health care providers should be assigned the special role in the process of identification and assessment of severity of symptoms of depression and anxiety; thus, patients at risk of depression can receive a special medical supervision. This aims at increasing illness acceptance among patients with COPD and implementing rapid antidepressant treatment through education, relaxation therapy, behavioral therapy, and rehabilitation.

\section{Conclusion}

Illness acceptance has a significant impact mainly on the level of depression in patients with COPD. The level of illness acceptance is associated significantly with clinical manifestation of the disease and the severity of dyspnea. Apart from illness acceptance, smoking, lower education, and exacerbations have a significant impact on the occurrence of depression symptoms. Reduced acceptance of illness and severe dyspnea double the risk of occurrence of depression symptoms.

\section{Author contributions}

All authors contributed toward data analysis, drafting and revising the paper and agree to be accountable for all aspects of the work.

\section{Disclosure}

The authors report no conflicts of interest in this work.

\section{References}

1. Zielinski J. COPD-diagnosed too rarely, not only at an early-stage. Pneumonol Alergol Pol. 2007;75(1):2-4.

2. Sleszycka J, Woźniak K, Banaszek M, Wiechno W, Domagała-Kulawik J. Prevalence and difficulties in chronic obstructive pulmonary disease diagnosis in patients suffering from severe peripheral arterial disease. Pol Merkuriusz Lek. 2009;27(158):92-96.

3. Kalucka S. The occurrence of chronic obstructive pulmonary disease (COPD) in cigarette smoking families. Przegl Lek. 2006;63(10): 848-857.

4. Jenkins C, Rodríguez-Roisin R. Quality of life, stage severity and COPD. Eur Respir J. 2009;33(5):953-955.

5. Effing TW, Lenferink A, Buckman J, et al. Development of a selftreatment approach for patients with COPD and comorbidities: an ongoing learning process. J Thorac Dis. 2014;6(11):1597-1605.

6. Rennard SI, Drummond MB. Early chronic obstructive pulmonary disease: definition, assessment, and prevention. Lancet. 2015;385(9979): 1778-1788.

7. Curtis JR, Patrick DL. The assessment of health status among patients with COPD. Eur Respir J. 2003;21(41 Suppl):36s-45s.

8. Mikkelsen RL, Middelboe T, Pisinger C, Stage KB. Anxiety and depression in patients with chronić obstructive pulmonary disease (COPD) A review. Nord J Psychiatry. 2004;58(1):65-70.

9. Hill K, Geist R, Goldstein RS, Lacasse Y. Anxiety and depression in end-stage COPD. Eur Respir J. 2008;31(3):667-677.

10. Wagena EJ, Arrindell WA, Wouters EF, van Schayk CP. Are patients with COPD psychologically distressed? Eur Respir J. 2005;26(2): 242-248.

11. Dowson C, Laing R, Barraclough R, et al. The use of the Hospital Anxiety and Depression Scale (HADS) in patients with chronic obstructive pulmonary disease: a pilot study. $N Z$ Med J. 2001;114(1141):447-449.

12. Majda A, Jozefowska H. Psychological status patients with chronic obstructive pulmonary disease. Nurs Top. 2009;17(4):283-293.

13. Mroczek B, Sitko Z, Augustyniuk K, Pierzak-Sominka J, Wróblewska I, Kurpas D. Socioeconomic indicators shaping quality of life and illness acceptance in patients with chronic obstructive pulmonary disease. $A d v$ Exp Med Biol. 2015;861:19-30. 
14. Valero C, Monteagudo M, Llagostera M, et al; COPD Group of SAP Baix LLobregat Centre. Evaluation of a combined strategy directed towards health-care professionals and patients with chronic obstructive pulmonary disease (COPD): information and health education feedback for improving clinical monitoring and quality-of-life. $B M C$ Public Health. 2009;9:442.

15. Felton BJ, Revenson TA, Hinrichsen GA. Stress and coping in the explanation of psychological adjustment among chronically ill adults. Soc Sci Med. 1984;18(10):889-898.

16. Juczyński Z. Narzędzia pomiaru w promocji i psychologii zdrowia. Wydanie drugie [Measurement tools in the promotion and health psychology. second edition]. Warszawa: Pracowania Testów Psychologicznych; 2009.

17. Balcells E, Gea J, Ferrer J, et al. Factors affecting the relationship between psychological status and quality of life in COPD patients. Health Qual Life Outcomes. 2010;8:108.

18. Janssen DJA, Spruit MA, Leue C, et al. Symptoms of anxiety and depression in COPD patients entering pulmonary rehabilitation. Chron Respir Dis. 2010;7(3):147-157.

19. Yohannes AM, Willgoss TG, Baldwin RC, Connolly MJ. Depression and anxiety in chronic heart failure and chronic obstructive pulmonary disease: prevalence, relevance, clinical implications and management principles. Int J Geriatr Psychiatry. 2010;25(12):1209-1221.

20. Kupcewicz E, Abramowicz A. Assessment of quality of life in chronic obstructive pulmonary disease patients. Hygeia Pub Health. 2014; 49(4):805-812.

21. Rusin-Pawelek E, Uchmanowicz I, Jankowska-Polanska B, Panaszek B, Fal AM. Acceptance of illness of patients with bronchial asthma and asthma control. Alergol Info. 2012;7(3-4):61-67.

22. Kurowska I, Kasprzyk A. Disease acceptance and the ways of coping with stress in patients on dialysis. Psychiatr Psychol Klin. 2013;13(2): 99-107.

23. Niedzielski A, Humeniuk E, Błaziak P, Fedoruk D. The level of approval in selected chronic diseases. Wiad Lek. 2007;60(5-6):224-227.

24. Kieczka K. Quality of life in asthmatic patients and in chronic obstructive pulmonary disease from Mazowsze and Lublin Province. Nurs XXIst Century. 2010;32-33(1-2):17-23.

25. Gift AG, Wood RM, Cahill CA. Depression, somatization and steroid use in chronic obstructive pulmonary disease. Int J Nurs Stud. 1989;26(3): 281-286.

26. Wagena EJ, van Amelsvoort LGPM, Kant JI, Wouters EFM. Chronic bronchitis, cigarette smoking, and the subsequent onset of depression and anxiety: results from a prospective population-based cohort study. Psychosom Med. 2005;67:656-660.
27. Pooler A, Beech R. Examining the relationship between anxiety and depression and exacerbations of COPD which result in hospital admission: a systematic review. Int J COPD. 2014;9:315-330.

28. Ng TP, Niti M, Tan WC, Cao Z, Ong KC, Eng P. Depressive symptoms and chronic obstructive pulmonary disease: effect on mortality, hospital readmission, symptom burden, functional status, and quality of life. Arch Intern Med. 2007;167(1):60-67.

29. Coventry PA, Gemmell I, Todd CJ. Psychosocial risk factors for hospital readmission in COPD patients on early discharge services: a cohort study. BMC Pulm Med. 2011;11:49.

30. Regvat J, Zmitek A, Vegnuti M, Kosnik M, Suskovic S. Anxiety and depression during hospital treatment of exacerbation of chronic obstructive pulmonary disease. $J$ Int Med Res. 2011;39(3):1028-1038.

31. Cicutto LC, Brooks D. Self-care approaches to managing chronic obstructive pulmonary disease: a provincial survey. Respir Med. 2006; 100(9):1540-1546.

32. Asnaashari AM, Talaei A, Haghigh B. Evaluation of psychological studies in patients with asthma and COPD. Iran J Allergy Asthma Immunol. 2012;11(1):65-71.

33. Kühl K, Schürmann W, Rief W. Mental disorders and quality of life in COPD patients and their spouses. Int J Chron Obstruct Pulmon Dis. 2008;3(4):727-736.

34. Omachi TA, Katz PP, Yelin EH, et al. Clinical significance, depression and health-related quality of life in chronic obstructive pulmonary disease. Am J Med. 2009;122(8):778.e9-778.e15.

35. Maurer J, Rebbapragada V, Borson S, et al. ACCP workshop panel on anxiety and depression in COPD. Anxiety and depression in COPD: current understanding, unanswered questions, and research needs. Chest. 2008;134(4 suppl):43S-56S

36. Fan VS, Ramsey SD, Giardino ND, et al. Sex, depression, and risk of hospitalization and mortality in chronic obstructive pulmonary disease. Arch Intern Med. 2007;167(21):2345-2353.

37. Bourbeau J, Saad N, Joubert A, et al. Making collaborative selfmanagement successful in COPD patients with high disease burden. Respir Med. 2013;107(7):1061-1065.

38. Lenferink A, Frith P, van der Valk P, et al. A self-management approach using self-initiated action plans for symptoms with ongoing nurse support in patients with Chronic Obstructive Pulmonary Disease (COPD) and comorbidities: the COPE-III study protocol. Contemp Clin Trials. 2013;36(1):81-89.
International Journal of COPD

\section{Publish your work in this journal}

The International Journal of COPD is an international, peer-reviewed journal of therapeutics and pharmacology focusing on concise rapid reporting of clinical studies and reviews in COPD. Special focus is given to the pathophysiological processes underlying the disease, intervention programs, patient focused education, and self management protocols.

\section{Dovepress}

This journal is indexed on PubMed Central, MedLine and CAS. The manuscript management system is completely online and includes a very quick and fair peer-review system, which is all easy to use. Visit http://www.dovepress.com/testimonials.php to read real quotes from published authors. 